\title{
Autism spectrum disorder in children born preterm - role of exposure to perinatal inflammation
}

\author{
Suzanne J. Meldrum ${ }^{1,2, *}$, T. Strunk ${ }^{1,2}$, A. Currie ${ }^{1,2,3}$, S. L. Prescott ${ }^{1}$, K. Simmer ${ }^{1,2}$ and \\ A. J. O. Whitehouse ${ }^{4,5}$ \\ 1 School of Paediatrics and Child Health, The University of Western Australia, Crawley, Perth, WA, Australia \\ ${ }^{2}$ Centre for Neonatal Research and Education, University of Western Australia, Perth, WA, Australia \\ ${ }^{3}$ School of Veterinary and Life Sciences, Murdoch University, Murdoch, WA, Australia \\ ${ }^{4}$ Telethon Institute for Child Health Research, University of Western Australia, Crawley, WA, Australia \\ ${ }^{5}$ School of Psychology, University of Western Australia, Crawley, WA, Australia
}

Edited by:

Sarah J. Spencer, Monash

University, Australia

Reviewed by:

Luis M. Garcia-Segura, Consejo

Superior de Investigaciones

Cientificas, Spain

Trisha A. Jenkins, RMIT University, Australia

*Correspondence:

Suzanne J. Meldrum, School of

Paediatrics and Child Health

Research, Princess Margaret

Hospital, University of Western

Australia, PO Box D184, Perth WA

6001, Australia

e-mail:suzanne.meldrum@

uwa.edu.au
Autism Spectrum Disorder (ASD) is the collective term for neurodevelopmental disorders characterized by qualitative impairments in social interaction, communication, and a restricted range of activities and interests. Many countries, including Australia, have reported a dramatic increase in the number of diagnoses over the past three decades, with current prevalence of ASD at 1 in every 110 individuals ( 1\%). The potential role for an immune-mediated mechanism in ASD has been implicated by several studies, and some evidence suggests a potential link between prenatal infection-driven inflammation and subsequent development of ASD. Furthermore, a modest number of contemporary studies have reported a markedly increased prevalence of ASD in children born preterm, who are at highest risk of exposure to perinatal inflammation. However, the mechanisms that underpin the susceptibility to infection-driven inflammation during pregnancy and risk of preterm birth, and how these intersect with the subsequent development of ASD in the offspring, is not understood. This review aims to summarize and discuss the potential mechanisms and evidence for the role of prenatal infection on the central nervous system, and how it may increase the susceptibility for ASD pathogenesis in children born preterm.

Keywords: preterm, autism spectrum disorders, prenatal infection, immunology

\section{INTRODUCTION}

Autism Spectrum Disorder (ASD) is the collective term for neurodevelopmental disorders characterized by qualitative impairments in social interaction, communication, and a restricted range of activities and interests (Association, 2000). Autistic Disorder, Pervasive Developmental Disorder-Not Otherwise Specified (PDD-NOS) and Asperger's Disorder differ with regard to the quality and quantity of symptoms, but are thought to share a similar genetic liability (Freitag, 2007). ASD is a growing public health concern. Many countries, including Australia (Williams et al., 2008b), have reported a dramatic increase in the number of ASD diagnoses over the past three decades from less than 1 in 1000 individuals with a form of ASD (Chakrabarti and Fombonne, 2001; Wing and Potter, 2002) to 1 in every $110(\sim 1 \%)$ (CDC, 2006). While some assessment factors may be responsible for part of the increase, including changes in diagnostic criteria, different assessment instruments and increased autism awareness (Matson and Kozlowski, 2011), several environmental and epigenetic factors have also been implicated. In particular, a range of perinatal exposures are associated with ASD, including heavy metal and pesticide exposure, stress, smoking, and use of anti-depressant medication during pregnancy and certain foods (Dietert et al., 2011). These same factors are also associated with preterm birth, and it is important to note that a number of contemporary studies have reported an increased prevalence of ASD in preterm populations (Kolevzon et al., 2007).

\section{PREMATURITY AND ASD}

A meta-analysis of seven retrospective epidemiologic studies, representing five different geographic locations concluded that the following factors were associated with an increased risk of ASD; low birth weight, reduced gestational age at birth, birth asphyxia, and advanced maternal age ( $>35$ years), along with a maternal place of birth outside Europe/North America (Kolevzon et al., 2007). A further five epidemiological studies published after 2007 found similar associations (Schendel and Bhasin, 2008; Williams et al., 2008a; Buchmayer et al., 2009; Schieve et al., 2011; Guinchat et al., 2012; Lampi et al., 2012; Movsas and Paneth, 2012), with the exception of Schieve et al. (2011), who found that prematurity did not account for a significant proportion of the increase in ASD prevalence. Yet this study addressed the predictive factors associated with the recent increase in ASD prevalence, rather than ASD diagnosis per se. A caveat to these findings, however, there was an over-representation of children with severe forms of ASD, indicating that these studies may suffer from self-selection bias.

In terms of gestational age, there is evidence that the qualitative and quantitative nature of ASD symptomatology may differ across gestational age bands. Movsas and Paneth (2012) identified that for infants born less than 34 weeks, the largest impairments were within the domains of social cognition, social communication and autistic mannerisms. For children born between 34 and 36 weeks, all domains were equally affected (Movsas and Paneth, 2012). 


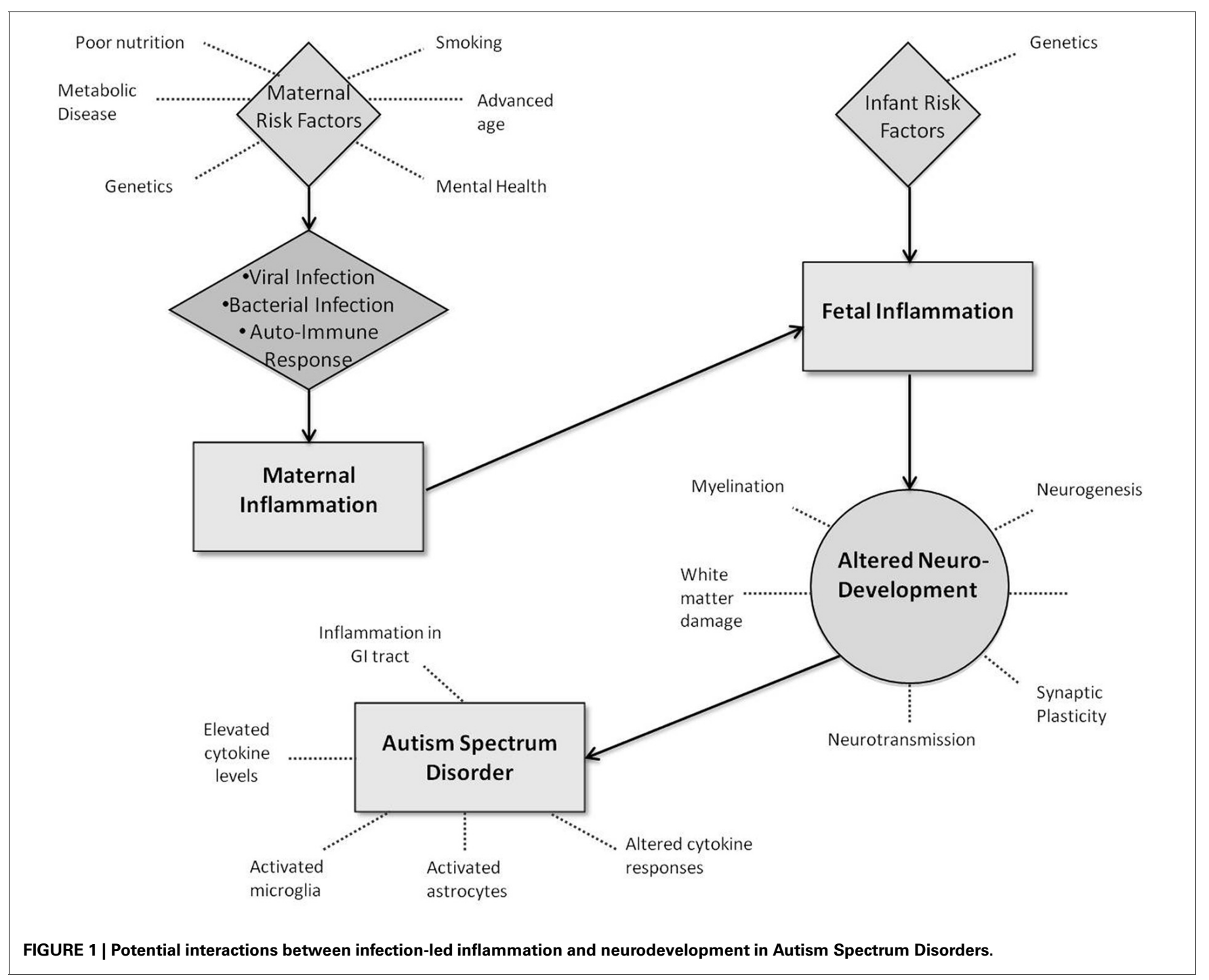

Several prospective studies of ASD in preterm population (based on parental questionnaire-based data) have demonstrated a comparatively elevated risk for ASD in preterm children, although the incidence of ASD varied widely between studies (19.4-41\%) (Sargent, 1993; Zenclussen et al., 2007; Limperopoulos et al., 2008; Hack et al., 2009; Kuban et al., 2009; Moore et al., 2012). The populations examined all consisted of extremely preterm children ( $<28$ weeks) or of very low birth weight $(<1500 \mathrm{~g})$, and the children were assessed for ASD at less than three years of age. Results should be interpreted with caution however, as the formal diagnosis of ASD is reached in significantly fewer individuals than implicated by positive questionnaire screening (Romero et al., 2003), and the incidence of positive screening for ASD is significantly higher for populations with other significant neurological, cognitive, and sensory sequelae (Coe and Lubach, 2005; Williams et al., 2008a).

Two prospective studies have included information on children formally diagnosed with ASD (Romero et al., 2006; Meyer et al., 2007). The first recruited 219 children (age 11 years) born before 26 weeks gestation in 1995 in the UK and Ireland and compared rates of ASD diagnosis to 152 children born at term (Meyer et al., 2007). Overall $8 \%$ of preterm children were assigned a diagnosis of ASD compared to none in the term group. Notably, $16 \%$ of preterm and $3 \%$ of term children screened positive based on a questionnaire alone, again emphasizing the need for caution when interpreting questionnaire-based screening data. Of those with a formal diagnosis, 13 had autistic disorder and three with PDD-NOS, representing a prevalence between 4 and 12 times higher than the general population (Meyer et al., 2007). The second study by Pinto-Martin and colleagues, recruited 623 infants of moderately low birth weight $(<2000 \mathrm{~g})$ born between 1984 and 1987 in NJ, USA (Romero et al., 2006). At age 21, the overall prevalence rate of ASD for the cohort was $5 \%$, whereas questionnaire screening identified $18.8 \%$ as positive.

In summary, these retrospective and prospective epidemiological studies provide some evidence that prematurity, measured either as gestational age or birth weight, increases the risk and 
alters the symptomology of ASD. Yet it remains clear that further large prospective cohort studies of children born preterm are required to confirm the exact incidence and identify other potentially modifying risk factors. Such research also does not resolve how prematurity could mechanistically lead to the development of ASD. The answer to this question may lie with one or more of the many recognized antecedents of preterm birth, in particular, exposure to maternal/fetal infection and inflammation.

\section{THE MATERNAL AND FETAL INFLAMMATORY RESPONSES TO INFECTION}

During pregnancy, maternal immunity is associated systemically with enhanced suppressor responses and greater susceptibility of the mother to a range of infections, particularly with viral and intracellular pathogens (Chheda et al., 1996). On an anatomical level, a range of active tolerance mechanisms, including the induction of regulatory $\mathrm{T}$ cells, hormones and anti-inflammatory cytokines, ensure that fetal rejection does not occur (Jones et al., 1996). Maternal infections can, and do result in inflammatory responses (Gotsch et al., 2007; Agrawal and Hirsch, 2012; Burd et al., 2012), and these are intimately related to the onset of spontaneous labor and preterm birth (Burd et al., 2009; Brown, 2011; Meyer et al., 2011). Additionally, ascending intrauterine bacterial infections are common among mothers who deliver preterm [up to 40\% (Brown, 2012)], and this is associated with placental inflammation as well as fetal inflammatory cytokine responses (Pararas et al., 2006).

Research suggests that exposure of the developing fetus, either directly to infection and inflammation, or indirectly via maternal inflammation, can impact on development of the CNS and therefore possibly contribute to ASD. This evidence will be discussed in turn. However, a causal relationship between infection-induced inflammation and ASD has not been formally established and important mechanistic questions remain.

\section{WHAT IS THE EVIDENCE FOR A ROLE OF PRENATAL INFECTION IN THE DEVELOPMENT OF ASD?}

Maternal prenatal infections have been linked to neurodevelopmental and neurological disorders, including cerebral palsy (Goldenberg et al., 2000, 2008), schizophrenia and ASD (Lamont and Sawant, 2005). An association between maternal infection and schizophrenia is supported by both human studies and animal pregnancy models (Chaiworapongsa et al., 2002). Hypotheses aimed at explaining this relationship have focused on the action of inflammatory cytokines on the developing fetal brain, or the induction of deleterious maternal autoimmune responses, as likely routes to altered neurodevelopment (Lamont and Sawant, 2005). As schizophrenia and ASD share both clinical and biological links, research has subsequently turned to evaluate the role of prenatal infection/inflammation and ASD (Gavilanes et al., 2009).

\section{BACTERIAL INFECTIONS}

Maternal bacterial infection during pregnancy is intrinsically linked with preterm delivery (Hatfield et al., 2011).
Chorioamnionitis (inflammation of the chorionic disc, maternal and/or fetal membranes, cord and/or amniotic fluid) is associated with approximately $25-40 \%$ of all preterm births (Wu, 2002; Wharton et al., 2004; Shatrov et al., 2010), and can result in elevated inflammatory markers in the amniotic fluid, cord and newborn peripheral blood and cerebrospinal fluid (Stephens et al., 2012). Alterations in brain morphology following prenatal exposure to chorioamnionitis have been reported, and include a decreased number of neurons in the cortex, hippocampus and substantia nigra (Samara et al., 2008) as well as diffuse global changes in cortical thickness (Johnson and Marlow, 2009). Exposure to clinical and histological chorioamnionitis has been associated with white matter injury and worse neurological outcomes, including cerebral palsy (Schendel et al., 2009; Johnson et al., 2010). Importantly, the presence of a fetal inflammatory response appears more predictive of brain injury than maternal inflammation (Redline et al., 1998, 2000; Yoon et al., 2000, 2001; Pinto-Martin et al., 2011).

Few studies have addressed the potential association between maternal bacterial infections and ASD. In 2010, Atladottir et al. $(2010 a, b)$ reported an association between maternal bacterial infection during the second trimester and the diagnosis of ASD in the child (adjusted hazard ration of 1.42). They were not able to discern the causative pathogens associated with this effect, but noted that the most common infections were urogenital $(\sim 75 \%)$ and suggested that the observed association could be due to "transplacental passage of maternally produced cytokines or antibodies in response to the infection" (p. 1429). Limperopoulos et al. (2008) observed that for 91 very low birth weight infants, chorioamnionitis was significantly associated with an abnormal autism screening score, with an OR of 9.669 (95\% CI 3.302-28.310). In contrast to the above studies, Abdallah et al. found no significant associations between prenatal maternal infections (outpatient and hospital admissions) and the development of ASD (Abdallah et al., 2012).

Studies using animal models support the findings in humans and have identified an increased risk of several behaviors characteristic of ASD in the offspring of lipopolysaccharide (LPS)-activated mothers (Malkova et al., 2012). Such deficits include communication (ultrasonic vocalizations) (Malkova, 2010), social interaction (Smith et al., 2007), elevated anxiety and inhibition deficits (Patterson, 2009; Meyer and Feldon, 2010).

\section{VIRAL INFECTIONS}

There is less evidence that viral infections can increase the risk preterm birth in comparison to bacterial infections (Srinivas et al., 2006). Nevertheless, maternal viral infection is often associated with an increase in the incidence of psychiatric disorders with a neurodevelopmental origin, particularly schizophrenia (Brown and Patterson, 2011). Maternal influenza infection during the first trimester has also been associated with an increased risk of ASDs in the offspring in a study by Atladottir et al. (2010a). This finding is supported by laboratory evidence, whereby an influenza infection induced the gene expression of various proinflammatory and chemo-attractive cytokines in 
cultured human fetal membrane cells (Uchide et al., 2005). Furthermore, respiratory infection with the human influenza virus at mid-gestation in animal models results in behavioral and pharmacological abnormalities (Patterson, 2002; Shi et al., 2003), along with widespread reduction in gray matter volume in the cortex and reduced white matter volume in the parietal cortex (Short et al., 2010). The Atladottir and colleagues study was also subject to bias, as they were based on infections requiring admission to hospital, and did not include subclinical infections, or those treated by general practitioner.

Other viruses for which a potential association with ASD and related disorders have been suggested include congenital rubella (Freedman et al., 1970; Chess, 1971, 1977; Stubbs, 1995), herpes, cytomegalovirus (Stern and Tucker, 1973; Stubbs, 1978; Markowitz, 1983; Ivarsson et al., 1990; Ciaranello and Ciaranello, 1995; Yamashita et al., 2003; Sweeten et al., 2004), varicella (Ciaranello and Ciaranello, 1995), mumps (Ciaranello and Ciaranello, 1995), polyomavirus (Lintas et al., 2010) and enterovirus (Sadeharju et al., 2003; Johnson et al., 2009a). However, these infections are relatively uncommon and therefore evidence is restricted to case reports and hypotheses.

\section{MATERNAL AUTOIMMUNE CONDITIONS}

Epidemiological studies show that autoimmune diseases (rheumatoid arthritis, celiac disease, type 1 diabetes) are more common in mothers of children diagnosed with ASD than in mothers of children without developmental abnormalities (Atladottir et al., 2010b; Ashwood et al., 2011a). Animal studies have demonstrated that injections of rodents or rhesus macaques during mid-gestation with immunoglobulins isolated from human mothers of children with ASD results in abnormal stereotypic behaviors in their offspring (Martin et al., 2008; Singer et al., 2009). Furthermore, subsets of mothers of children with ASD have circulating antibodies which target fetal brain proteins [as reviewed in Wills et al. (2007)]. Immune responses to viral infections commonly result in transiently elevated levels of autoantibodies (Ludewig et al., 2004). It is therefore conceivable that increased maternal autoimmune reactivity following viral infections may effect fetal brain development, however, further studies are needed to support this hypothesis.

\section{HOW COULD INFECTION-DRIVEN INFLAMMATION RESULT IN ASD? EFFECTS ON BRAIN STRUCTURE AND FUNCTION}

Intrauterine inflammation is increasingly being recognized as a key contributor to adverse neurological outcomes in infants born preterm (Goines et al., 2011). Evidence suggests that infants and children with ASD exhibit altered immunological status relative to unaffected children. For example, increased levels of pro-inflammatory cytokines (IFN $\gamma$ and IL-6) were observed in the mid-gestation serum of a mother who went onto deliver a child with ASD. Further, post-mortem studies of brain and cerebrospinal fluid of individuals with ASD (8/13 by drowning) have shown an higher degree of inflammation with elevated cytokine levels and activated microglia and astrocytes compared to control subjects (Morgan et al., 2010; Lintas et al.,
2012). Subjects have ranged in age, indicating that this immuneactivation may begin in early life and be long-lasting (Chez et al., 2007; Morgan et al., 2010). In addition, peripheral blood mononuclear cells display altered cytokine responses to stimulation in vitro (Enstrom et al., 2010; Ashwood et al., 2011b; Goines and Ashwood, 2013) along with inflammation in the gastrointestinal tract of a subset of ASD children (Ashwood, 2010; Buie et al., 2010). This may be especially relevant as proinflammatory cytokines (e.g., TNF $\alpha$, IFN $\gamma$, IL-1, IL-6, and IL-8) are involved in the pathogenesis of preterm infant brain injury, predominantly white matter damage (Dammann and Leviton, 1997; Yoon et al., 1997a,b; Patrick and Smith, 2002), and adversely affect neurodevelopmental processes, including neurogenesis, neuronal migration, synaptic plasticity, neurotransmission, and myelination (Zhu et al., 2002; Bauer et al., 2007; Rostene et al., 2007). Microarray studies have also shown dysregulation of several ASD candidate genes known to regulate both brain and immune system development (Careaga et al., 2010; Lintas et al., 2012).

It is difficult, however, to attribute infection-related inflammation to aberrant CNS development in individuals with ASD as ASD is a complex disorder with no common cellular, molecular or systems level unification. Yet the preterm infant may be at particular risk of neurodevelopmental disability, due to a birth occurring during the $2^{\text {nd }}$ trimester $\left(23^{\text {rd }}\right.$ to $27^{\text {th }}$ weeks) when the brain is particularly vulnerable to a heightened inflammatory state. Such a time corresponds to the transformation of oligodendrocytes, migration of neuron precursors from the germinal plate, and the up-regulation of excitatory neurotransmitter pathways. Such factors can be linked to the several neurodevelopmental anomalies noted in ASD (Shinohe et al., 2006; Hughes, 2007; Bassett and Bullmore, 2009; Wegiel et al., 2010; Deoni et al., 2011; Essa et al., 2012).

\section{THE ROLE OF MODIFIERS}

Despite the emerging evidence for the association between maternal infection/inflammation and ASD, this relationship is not universal to all cases of ASD. This is expected, considering the large heterogeneity of ASD symptomology, and the number of risk factors currently described. It is therefore likely that specific modifying factors influence this association, effecting either protective or injurious susceptibility to ASD risk. Firstly, the interaction of infection/inflammation and ASD risk may be modulated by maternal factors during pregnancy including smoking, age, mental health and metabolic disease. And secondly, the clinical presentation among individuals may be due to gene-gene or gene-environment interaction. All modifying factors are unlikely to singularly affect susceptibility, but are likely to be inter-related and accumulative.

Several maternal factors may increase the likelihood of preterm birth including smoking during pregnancy (Simpson, 1957; Schwartz et al., 1972; Berkowitz and Papiernik, 1993; Kaminski, 1997; Shah and Bracken, 2000; Bada et al., 2005; Kyrklund-Blomberg et al., 2005; Ng and Zelikoff, 2007; McCowan et al., 2009; Thiriez et al., 2009), age greater than 35 years 
(Cnattingius et al., 1992; Fraser et al., 1995; Gilbert et al., 1999; Ananth et al., 2001; Jacobsson et al., 2004), metabolic syndrome (Rey and Couturier, 1994; Catov et al., 2007a,b, 2008, 2010; Edison et al., 2007; Gilbert et al., 2007; Salihu et al., 2008; Chatzi et al., 2009; Ehrenberg et al., 2009; Johnson et al., 2009b), poor nutritional status (Cogswell et al., 2003; Siega-Riz et al., 2006; Bodnar et al., 2010; Czeizel et al., 2010) and mental health (Blondel et al., 1990; Oakley et al., 1990; Bryce et al., 1991; Hedegaard et al., 1996). Several of these factors can also modulate the level of maternal inflammation during pregnancy. For example, pregnancy stress results in the section of corticotrophinreleasing hormone (CRH) from the hypothalamus, and increased plasma levels of CRH have been linked to preterm labor (Hobel et al., 1999). While some evidence suggests that such maternal risk factors can contribute to the development of ASD (Rizzo et al., 1997; Croen et al., 2002, 2007; Hultman et al., 2002; Glasson et al., 2004; Beversdorf et al., 2005; Larsson et al., 2005; Lauritsen et al., 2005; Leonard et al., 2006; Reichenberg et al., 2006; Dionne et al., 2008; Durkin et al., 2008; Grant and Soles, 2009; Grether et al., 2009; King et al., 2009; Li et al., 2009a,b; Burstyn et al., 2010; James et al., 2010; Kalkbrenner et al., 2012; Meguid et al., 2010; Roza et al., 2010; Shelton et al., 2010; Dodds et al., 2011; Lee et al., 2012; Parner et al., 2012; Rai et al., 2012; Sandin et al., 2012; Schmidt et al., 2012), results remain largely mixed and are strongest for advanced maternal age.

Variable distributions of genetic polymorphisms associated with the inflammatory response may be related to the risk of ASD development in the presence of a intrauterine infection/inflammation (Nelson et al., 2005; Wu et al., 2009). Inherited cytokine or chemokine polymorphisms influence the risk for pre

\section{REFERENCES}

Abdallah, M. W., Hougaard, D. M., Norgaard-Pedersen, B., Grove, J., Bonefeld-Jorgensen, E. C., and Mortensen, E. L. (2012). [Infections during pregnancy and after birth, and the risk of autism spectrum disorders: a register-based study utilizing a danish historic birth cohort]. Turk. Psikiyatri. Derg. 23, 229-236.

Adcock, K., Hedberg, C., Loggins, J., Kruger, T. E., and Baier, R. J. (2003). The TNF-alpha -308, MCP$1-2518$ and TGF-betal +915 polymorphisms are not associated with the development of chronic lung disease in very low birth weight infants. Genes Immun. 4, 420-426. doi: 10.1038/sj.gene.6363986

Agrawal, V., and Hirsch, E. (2012). Intrauterine infection and preterm labor. Semin. Fetal Neonatal Med. 17, 12-19. doi: 10.1016/j.siny.2011.09.001

Ananth, C. V., Misra, D. P., Demissie, K., and Smulian, J. C. (2001). Rates of preterm delivery among Black women and White women in the United States over two decades:

and perinatal brain damage contributing to cognitive impairment (Harding et al., 2005), intraventricular hemorrhage (Adcock et al., 2003; Heep et al., 2005) and cerebral palsy (Nelson et al., 2005; Gibson et al., 2006; Wu et al., 2009). The first comprehensive gene-expression analysis of the CNS in patients with ASD (Voineagu et al., 2011), observed that immune genes and glial markers were over-expressed, supporting the findings of immune dysregulation in ASD. An epidemiological study recently observed that while siblings of children with ASD had fewer prenatal or perinatal complications than their affected siblings, such complications were significant higher than control subjects (Glasson et al., 2004). Suggesting that siblings of children with ASD have reacted differently to similar environmental stimuli, perhaps due to altered gene-environment interactions.

\section{CONCLUSIONS}

We have summarized the extant research that preterm infants may be at increased risk of developing ASD, and how maternal infection/inflammation along with modifying gene-environment interactions may be a predisposing factor. While the underlying mechanism is not understood, the association between maternal infection/inflammation provides a promising field of enquiry. There is an evident lack of large-scale prospective studies: (i) to ascertain the true incidence of ASD among children born preterm and (ii) To characterize the risk factors preterm infants who develop ASD, specifically maternal infection/inflammation. Such future studies could also have preventative implications, where treatment to minimize such risk factors could be better implemented to minimize the risk of children born preterm developing ASD.

Text Revision ed. Washington, DC: American Psychiatric Association.

an age-period-cohort analysis. Am. J. Epidemiol. 154, 657-665. doi: 10.1093/aje/154.7.657

Ashwood, P. (2010). "Autism, gastrointestinal disturbance, and immune dysfunction: what is the link," in Autism: Oxidative Stress, Inflammation, and Immune Abnormalities, eds A. V. Chauhan, T. Chauhan, and T. W. Brown (Boca Raton, FL: CRC Press), 277-299. doi: 10.1186/2040-2392-2-13

Ashwood, P., Krakowiak, P., HertzPicciotto, I., Hansen, R., Pessah, I. N., and Van de Water, J. (2011a). Associations of impaired behaviors with elevated plasma chemokines in autism spectrum disorders. J. Neuroimmunol. 232, 196-199. doi: 10.1016/j.jneuroim.2010.10.025

Ashwood, P., Krakowiak, P., HertzPicciotto, I., Hansen, R., Pessah, I. N., and Van de Water, J. (2011b). Altered T cell responses in children with autism. Brain Behav. Immun. 25, 840-849. doi: 10.1016/j.bbi.2010.09.002

Association, A. P. (2000). Diagnostic and Statistical Manual of Mental Disorders (DSM-IV), 4th Edn.,
Atladottir, H. O., Thorsen, P., Ostergaard, L., Schendel, D. E., Lemcke, S., Abdallah, M., et al. (2010a). Maternal infection requiring hospitalization during pregnancy and autism spectrum disorders. J. Autism Dev. Disord. 40, 1423-1430. doi: 10.1007/s10803-010-1006-y

Atladottir, H. O., Thorsen, P., Schendel, D. E., Ostergaard, L., Lemcke, S., and Parner, E. T. (2010b). Association of hospitalization for infection in childhood with diagnosis of autism spectrum disorders: a Danish cohort study. Arch. Pediatr. Adolesc. Med. 164, 470-477. doi: 10.1001/archpediatrics.2010.9

Bada, H. S., Das, A., Bauer, C. R., Shankaran, S., Lester, B. M., Gard, C. C., et al. (2005). Low birth weight and preterm births: etiologic fraction attributable to prenatal drug exposure. J. Perinatol. 25, 631-637. doi: 10.1038/sj.jp.7211378

Bassett, D. S., and Bullmore, E. T. (2009). Human brain networks in health and disease. Curr.
Opin. Neurol. 22, 340-347. doi: 10.1097/WCO.0b013e32832d93dd

Bauer, S., Kerr, B. J., and Patterson, P. H. (2007). The neuropoietic cytokine family in development, plasticity, disease and injury. Nat. Rev. Neurosci. 8, 221-232. doi: $10.1038 / \mathrm{nrn} 2054$

Berkowitz, G. S., and Papiernik, E. (1993). Epidemiology of preterm birth. Epidemiol. Rev. 15, 414-443.

Beversdorf, D. Q., Manning, S. E., Hillier, A., Anderson, S. L., Nordgren, R. E., Walters, S. E., et al. (2005). Timing of prenatal stressors and autism. J. Autism Dev. Disord. 35, 471-478. doi: 10.1007/s10803-005-5037-8

Blondel, B., Breart, G., Llado, J., and Chartier, M. (1990). Evaluation of the home-visiting system for women with threatened preterm labor: results of a randomized controlled trial. Eur. J. Obstet. Gynecol. Reprod. Biol. 34, 47-58. doi: 10.1016/0028-224390006-M

Bodnar, L. M., Himes, K. P., Venkataramanan, R., Chen, J.Y., Evans, R. W., Meyer, J. L., et al. (2010). Maternal serum folate 
species in early pregnancy and risk of preterm birth. Am. J. Clin. Nutr. 92, 864-871.

Brown, A. S. (2011). Exposure to prenatal infection and risk of schizophrenia. Front. Psychiatry 2:63. doi: 10.3389/fpsyt.2011.00063

Brown, A. S. (2012). Epidemiologic studies of exposure to prenatal infection and risk of schizophrenia and autism. Dev. Neurobiol. 72, 1272-1276. doi: 10.1002/dneu.22024

Brown, A. S., and Patterson, P. H. (2011). Maternal infection and schizophrenia: implications for prevention. Schizophr. Bull. 37, 284-290. doi: 10.1093/schbul/ sbq146

Bryce, R. L., Stanley, F. J., and Garner, J. B. (1991). Randomized controlled trial of antenatal social support to prevent preterm birth. Br. J. Obstet. Gynaecol. 98, 1001-1008. doi: 10.1111/j.14710528.1991.tb15338.x

Buchmayer, S., Johansson, S., Johansson, A., Hultman, C. M., Sparen, P., and Cnattingius, S. (2009). Can association between preterm birth and autism be explained by maternal or neonatal morbidity. Pediatrics 124, e817-e825. doi: 10.1542/peds. 2008-3582

Buie, T., Campbell, D. B., Fuchs, G. J. 3rd, Furuta, G. T., Levy, J., Vandewater, J., et al. (2010). Evaluation, diagnosis, and treatment of gastrointestinal disorders in individuals with ASDs: a consensus report. Pediatrics 125 (Suppl. 1), S1-S18. doi: 10.1186/2040-2392-2-13

Burd, I., Balakrishnan, B., and Kannan, S. (2012). Models of fetal brain injury, intrauterine inflammation, and preterm birth. Am. J. Reprod. Immunol. 67, 287-294. doi: 10.1111/j.1600-0897.2012.01110.x

Burd, I., Chai, J., Gonzalez, J., Ofori, E., Monnerie, H., Le Roux, P. D., et al. (2009). Beyond white matter damage: fetal neuronal injury in a mouse model of preterm birth. Am. J. Obstet. Gynecol. 201, 279.e1-279.e8.

Burstyn, I., Sithole, F., and Zwaigenbaum, L. (2010). Autism spectrum disorders, maternal characteristics and obstetric complications among singletons born in Alberta, Canada. Chronic Dis. Can. $30,125-134$

Careaga, M., Van de Water, J., and Ashwood, P. (2010). Immune dysfunction in autism: a pathway to treatment. Neurotherapeutics 7, 283-292. doi: 10.1016/j.nurt. 2010.05 .003
Catov, J. M., Bodnar, L. M., Kip, K. E., Hubel, C., Ness, R. B., Harger, G., et al. (2007a). Early pregnancy lipid concentrations and spontaneous preterm birth. Am. J. Obstet. Gynecol. 197, 610.e1-610.e7.

Catov, J. M., Bodnar, L. M., Ness, R. B., Barron, S. J., and Roberts, J. M. (2007b). Inflammation and dyslipidemia related to risk of spontaneous preterm birth. Am. J. Epidemiol. 166, 1312-1319. doi: 10.1093/aje/ kwm273

Catov, J. M., Ness, R. B., Wellons, M. F., Jacobs, D. R., Roberts, J. M., and Gunderson, E. P. (2010). Prepregnancy lipids related to preterm birth risk: the coronary artery risk development in young adults study. J. Clin. Endocrinol. Metab. 95, 3711-3718. doi: 10.1210/jc.20092028

Catov, J. M., Nohr, E. A., Olsen, J., and Ness, R. B. (2008). Chronic hypertension related to risk for preterm and term small for gestational age births. Obstet. Gynecol. 112(2 Pt 1), 290-296. doi: 10.1097/AOG.0b013e31817f589b

Centers for Disease Control and Prevention. (2006). Prevalence of autism spectrum disorders-autism and developmental disabilities monitoring network. MMWR Surveill Summ. 58, 1-20.

Chaiworapongsa, T., Romero, R., Kim, J. C., Kim, Y. M., Blackwell, S. C., Yoon, B. H., et al. (2002). Evidence for fetal involvement in the pathologic process of clinical chorioamnionitis. Am. J. Obstet. Gynecol. 186, 1178-1182. doi: 10.1067/mob.2002.124042

Chakrabarti, S., and Fombonne, E. (2001). Pervasive developmental disorders in preschool children. JAMA 285, 3093-3099. doi: 10.1001/jama.285.24.3093

Chatzi, L., Plana, E., Daraki, V., Karakosta, P., Alegkakis, D., Tsatsanis, C., et al. (2009). Metabolic syndrome in early pregnancy and risk of preterm birth. Am. J. Epidemiol. 170, 829-836.

Chess, S. (1971). Autism in children with congenital rubella. J. Autism Child Schizophr. 1, 33-47. doi: 10.1007/BF01537741

Chess, S. (1977). Follow-up report on autism in congenital rubella. J. Autism Child Schizophr. 7, 69-81. doi: 10.1007/BF01531116

Chez, M. G., Dowling, T., Patel, P. B., Khanna, P., and Kominsky, M. (2007). Elevation of tumor necrosis factor-alpha in cerebrospinal fluid of autistic children. Pediatr.
Neurol. 36, 361-365. doi: 10.1016/j. pediatrneurol.2007.01.012

Chheda, S., Palkowetz, K. H., Garofalo, R., Rassin, D. K., and Goldman, A. S. (1996). Decreased interleukin-10 production by neonatal monocytes and $\mathrm{T}$ cells: relationship to decreased production and expression of tumor necrosis factoralpha and its receptors. Pediatr. Res. 40, 475-483. doi: 10.1203/ 00006450-199609000-00018

Ciaranello, A. L., and Ciaranello, R. D. (1995). The neurobiology of infantile autism. Annu. Rev. Neurosci. 18, 101-128. doi: 10.1146/ annurev.ne.18.030195.000533

Cnattingius, S., Forman, M. R., Berendes, H. W., and Isotalo, L. (1992). Delayed childbearing and risk of adverse perinatal outcome. A population-based study. JAMA 268, 886-890. doi: 10.1001/ jama.1992.03490070068044

Coe, C. L., and Lubach, G. R. (2005). Prenatal origins of individual variation in behavior and immunity. Neurosci. Biobehav. Rev. 29, 39-49. doi: 10.1016/j.neubiorev.2004.11.003

Cogswell, M. E., Parvanta, I., Ickes, L., Yip, R., and Brittenham, G. M. (2003). Iron supplementation during pregnancy, anemia, and birth weight: a randomized controlled trial. Am. J. Clin. Nutr. 78, 773-781.

Croen, L. A., Grether, J. K., and Selvin, S. (2002). Descriptive epidemiology of autism in a California population: who is at risk. J. Autism Dev. Disord. 32, 217-224. doi: 10.1023/A:1015405914950

Croen, L. A., Najjar, D. V., Fireman, B., and Grether, J. K. (2007). Maternal and paternal age and risk of autism spectrum disorders. Arch. Pediatr. Adolesc. Med. 161, 334-340. doi: 10.1001/archpedi.161.4.334

Czeizel, A. E., Puho, E. H., Langmar, Z., Acs, N., and Banhidy, F. (2010). Possible association of folic acid supplementation during pregnancy with reduction of preterm birth: a populationbased study. Eur. J. Obstet Gynecol. Reprod. Biol. 148, 135-140. doi: 10.1016/j.ejogrb.2009.10.016

Dammann, O., and Leviton, A. (1997). Maternal intrauterine infection, cytokines, and brain damage in the preterm newborn. Pediatr. Res. 42, 1-8. doi: 10.1203/00006450199707000-00001

Deoni, S. C., Mercure, E., Blasi, A., Gasston, D., Thomson, A., Johnson, M., et al. (2011). Mapping infant brain myelination with magnetic resonance imaging.
J. Neurosci. 31, 784-791. doi: 10.1523/JNEUROSCI.2106-10.2011

Dietert, R. R., Dietert, J. M., and DeWitt, J. C. (2011). Environmental risk factors for autism. Emerging Health Threats. 4, 1-11.

Dionne, G., Boivin, M., Seguin, J. R., Perusse, D., and Tremblay, R. E. (2008). Gestational diabetes hinders language development in offspring. Pediatrics 122, e1073-e1079. doi: 10.1542/peds.2007-3028

Dodds, L., Fell, D. B., Shea, S., Armson, B. A., Allen, A. C., and Bryson, S. (2011). The role of prenatal, obstetric and neonatal factors in the development of autism. J. Autism Dev. Disord. 41, 891-902. doi: 10.1007/s10803-010-1114-8

Durkin, M. S., Maenner, M. J., Newschaffer, C. J., Lee, L. C., Cunniff, C. M., Daniels, J. L., et al. (2008). Advanced parental age and the risk of autism spectrum disorder. Am. $J$. Epidemiol. 168, 1268-1276. doi: 10.1093/aje/kwn250

Edison, R. J., Berg, K., Remaley, A., Kelley, R., Rotimi, C., and Stevenson, R. E. (2007). Adverse birth outcome among mothers with low serum cholesterol. Pediatrics 120, 723-733. doi: 10.1542/peds.2006-1939

Ehrenberg, H. M., Iams, J. D., Goldenberg, R. L., Newman, R. B., Weiner, S. J., Sibai, B. M., et al. (2009). Maternal obesity, uterine activity, and the risk of spontaneous preterm birth. Obstet. Gynecol. 113, 48-52.

Enstrom, A. M., Onore, C. E., Van de Water, J. A., and Ashwood, P. (2010). Differential monocyte responses to TLR ligands in children with autism spectrum disorders. Brain Behav. Immun. 24, 64-71. doi: 10.1016/j.bbi.2009.08.001

Essa, M. M., Braidy, N., Vijayan, K. R., Subash, S., and Guillemin, G. J. (2012). Excitotoxicity in the Pathogenesis of Autism. Neurotox. Res. 23, 393-400. doi: 10.1007/s12640-012-9354-3

Fraser, A. M., Brockert, J. E., and Ward, R. H. (1995). Association of young maternal age with adverse reproductive outcomes. N. Engl. J. Med. 332, 1113-1117. doi: 10.1056/NEJM199504273321701

Freedman, D. A., Fox-Kolenda, B. J., and Brown, S. L. (1970). A multihandicapped rubella baby. J. Am. Acad. Child Psychiatry 9, 298-317. doi: 10.1016/S0002713861839-2

Freitag, C. M. (2007). The genetics of autistic disorders and its clinical relevance: a review of the 
literature. Mol. Psychiatry 12, 2-22. doi: 10.1038/sj.mp.4001896

Gavilanes, A. W., Strackx, E., Kramer, B. W., Gantert, M., Van den Hove, D., Steinbusch, H., et al. (2009). Chorioamnionitis induced by intraamniotic lipopolysaccharide resulted in an interval-dependent increase in central nervous system injury in the fetal sheep. Am. J. Obstet. Gynecol. 200, 437.e1-437.e8.

Gibson, C. S., MacLennan, A. H., Goldwater, P. N., Haan, E. A., Priest, K., Dekker, G. A., et al. (2006). The association between inherited cytokine polymorphisms and cerebral palsy. Am. J. Obstet. Gynecol. 194, 674.e1-674.e11.

Gilbert, W. M., Nesbitt, T. S., and Danielsen, B. (1999). Childbearing beyond age 40: pregnancy outcome in 24, 032 cases. Obstet. Gynecol. 93, 9-14. doi: 10.1016/S0029-784400382-2

Gilbert, W. M., Young, A. L., and Danielsen, B. (2007). Pregnancy outcomes in women with chronic hypertension: a populationbased study. J. Reprod. Med. 52, 1046-1051.

Glasson, E. J., Bower, C., Petterson, B., de Klerk, N., Chaney, G., and Hallmayer, J. F. (2004). Perinatal factors and the development of autism: a population study. Arch. Gen. Psychiatry 61, 618-627. doi: 10.1001/archpsyc.61.6.618

Goines, P. E., and Ashwood, P. (2013). Cytokine dysregulation in autism spectrum disorders (ASD): possible role of the environment. Neurotoxcol. Teratol. 36, 67-81. doi: 10.1016/j.ntt.2012.07.006

Goines, P. E., Croen, L. A., Braunschweig, D., Yoshida, C. K., Grether, J., Hansen, R., et al. (2011). Increased midgestational IFN-gamma, IL-4 and IL-5 in women bearing a child with autism: a case-control study. Mol. Autism 2:13. doi: $10.1186 / 2040-2392-2-13$

Goldenberg, R. L., Culhane, J. F., Iams, J. D., and Romero, R. (2008). Epidemiology and causes of preterm birth. Lancet 371, 75-84. doi: 10.1016/S0140-673660074-4

Goldenberg, R. L., Hauth, J. C., and Andrews, W. W. (2000). Intrauterine infection and preterm delivery. N. Engl. J. Med. 342, 1500-1507. doi: 10.1056/NEJM200005183422007

Gotsch, F., Romero, R., Kusanovic, J. P., Mazaki-Tovi, S., Pineles, B. L., Erez, O., et al. (2007). The fetal inflammatory response syndrome. Clin. Obstet. Gynecol. 50, 652-683. doi: 10.1097/GRF.0b013e31811ebef6
Grant, W. B., and Soles, C. M. (2009). Epidemiologic evidence for supporting the role of maternal vitamin D deficiency as a risk factor for the development of infantile autism. Dermatoendocrinology 1, 223-228. doi: 10.4161/derm. 1.4 .9500

Grether, J. K., Anderson, M. C., Croen, L. A., Smith, D., and Windham, G. C. (2009). Risk of autism and increasing maternal and paternal age in a large north American population. Am. J. Epidemiol. 170, 1118-1126. doi: 10.1093/aje/kwp247

Guinchat, V., Thorsen, P., Laurent, C., Cans, C., Bodeau, N., and Cohen, D. (2012). Pre-, peri- and neonatal risk factors for autism. Acta Obstet. Gynecol. Scand. 91, 287-300. doi: 10.1111/j.1600-0412.2011.01325.x

Hack, M., Taylor, H. G., Schluchter, M., Andreias, L., Drotar, D., and Klein, N. (2009). Behavioral outcomes of extremely low birth weight children at age 8 years. J. Dev. Behav. Pediatr. 30, 122-130. doi: 10.1097/DBP.0b013e31819e6a16

Harding, D., Brull, D., Humphries, S. E., Whitelaw, A., Montgomery, H., and Marlow, N. (2005). Variation in the interleukin-6 gene is associated with impaired cognitive development in children born prematurely: a preliminary study. Pediatr. Res. 58, 117-120. doi: 10.1203/ 01.PDR.0000163523.49021.53

Hatfield, T., Wing, D. A., Buss, C., Head, K., Muftuler, L. T., and Davis, E. P. (2011). Magnetic resonance imaging demonstrates longterm changes in brain structure in children born preterm and exposed to chorioamnionitis. Am. J. Obstet. Gynecol. 205, 384.e1-384.e8.

Hedegaard, M., Henriksen, T. B., Secher, N. J., Hatch, M. C., and Sabroe, S. (1996). Do stressful life events affect duration of gestation and risk of preterm delivery. Epidemiology 7 , 339-345. doi: 10.1097/ 00001648-199607000-00001

Heep, A., Schueller, A. C., Kattner, E., Kroll, M., Sander, J., Wisbauer, M., et al. (2005). Association of two tumour necrosis factor gene polymorphisms with the incidence of severe intraventricular haemorrhage in preterm infants. J. Med. Genet. 42, 604-608. doi: 10.1136/jmg.2004.021378

Hobel, C. J., Dunkel-Schetter, C., Roesch, S. C., Castro, L. C., and Arora, C. P. (1999). Maternal plasma corticotropinreleasing hormone associated with stress at 20 weeks' gestation in pregnancies ending in preterm delivery. Am. J. Obstet. Gynecol. 180(1 Pt 3), S257-S263. doi 10.1016/S0002-937870712-X

Hughes, J. R. (2007). Autism: the first firm finding $=$ underconnectivity. Epilepsy Behav. 11, 20-24. doi: 10.1016/j.yebeh.2007.03.010

Hultman, C. M., Sparen, P., and Cnattingius, S. (2002). Perinatal risk factors for infantile autism. Epidemiology 13, 417-423. doi: 10.1097/00001648-20020700000009

Ivarsson, S. A., Bjerre, I., Vegfors, P., and Ahlfors, K. (1990). Autism as one of several disabilities in two children with congenital cytomegalovirus infection. Neuropediatrics 21, 102-103. doi: 10.1055/s-2008-1071471

Jacobsson, B., Ladfors, L., and Milsom, I. (2004). Advanced maternal age and adverse perinatal outcome. Obstet. Gynecol. 104, 727-733. doi: 10.1097/ 01.AOG.0000140682.63746.be

James, S. J., Melnyk, S., Jernigan, S., Pavliv, O., Trusty, T., Lehman, S. et al. (2010). A functional polymorphism in the reduced folate carrier gene and DNA hypomethylation in mothers of children with autism. Am. J. Med. Genet. B Neuropsychiatr. Genet. 153B, 1209-1220.

Johnson, S., Hollis, C., Kochhar, P., Hennessy, E., Wolke, D., and Marlow, N. (2010). Autism spectrum disorders in extremely preterm children. J. Pediatr. 156, 525-531.e2.

Johnson, S., and Marlow, N. (2009). Positive screening results on the modified checklist for autism in toddlers: implications for very preterm populations. J. Pediatr. 154, 478-480. doi: 10.1016/j.jpeds.2008.11.028

Johnson, T. S., Rottier, K. J., Luellwitz, A., and Kirby, R. S. (2009b). Maternal prepregnancy body mass index and delivery of a preterm infant in missouri 1998-2000. Public Health Nurs. 26, 3-13. doi: 10.1111/j.1525-1446.2008.00750.x

Johnson, W. G., Buyske, S., Mars, A. E., Sreenath, M., Stenroos, E. S., Williams, T. A., et al. (2009a). HLADR4 as a risk allele for autism acting in mothers of probands possibly during pregnancy. Arch. Pediatr. Adolesc. Med. 163, 542-546. doi: 10.1001/archpediatrics.2009.74

Jones, C. A., Cayabyab, R. G., Kwong, K. Y., Stotts, C., Wong, B., Hamdan, H., et al. (1996). Undetectable interleukin (IL)-10 and persistent IL-8 expression early in hyaline membrane disease: a possible developmental basis for the predisposition to chronic lung inflammation in preterm newborns. Pediatr. Res. 39, 966-975. doi: 10.1203/00006450-19960600000007

Kalkbrenner, A. E., Braun, J. M., Durkin, M. S., Maenner, M. J., Cunniff, C., Lee, L. C., et al. (2012). Maternal smoking during pregnancy and the prevalence of autism spectrum disorders, using data from the autism and developmental disabilities monitoring network. Environ. Health Perspect. 120, 1042-1048. doi: 10.1289/ehp.1104556

Kaminski, M. (1997). ["Active" and "passive" smoking of pregnant women and risks to the child]. Bull. Acad. Natl. Med. 181, 754-763.

King, M. D., Fountain, C., Dakhlallah, D., and Bearman, P. S. (2009). Estimated autism risk and older reproductive age. Am. J. Public Health. 99, 1673-1679. doi 10.2105/AJPH.2008.149021

Kolevzon, A., Gross, R., and Reichenberg, A. (2007). Prenatal and perinatal risk factors for autism: a review and integration of findings. Arch Pediatr. Adolesc. Med. 161, 326-333. doi: 10.1001/archpedi.161.4.326

Kuban, K. C., O'Shea, T. M., Allred, E. N., Tager-Flusberg, H., Goldstein, D. J., and Leviton, A. (2009). Positive screening on the modified checklist for autism in toddlers (M-CHAT) in extremely low gestational age newborns. J. Pediatr. 154, 535-540.e1.

Kyrklund-Blomberg, N. B., Granath, F., and Cnattingius, S. (2005). Maternal smoking and causes of very preterm birth. Acta Obstet. Gynecol. Scand. 84, 572-577.

Lamont, R. F., and Sawant, S. R. (2005). Infection in the prediction and antibiotics in the prevention of spontaneous preterm labour and preterm birth. Minerva Ginecol. 57, 423-433.

Lampi, K. M., Lehtonen, L., Tran, P. L., Suominen, A., Lehti, V., Banerjee, P. N., et al. (2012). Risk of autism spectrum disorders in low birth weight and small for gestational age infants. J. Pediatr. 161, 830-836. doi: 10.1016/j.jpeds.2012.04.058

Larsson, H. J., Eaton, W. W., Madsen, K. M., Vestergaard, M., Olesen, A. V., Agerbo, E., et al. (2005). Risk factors for autism: perinatal factors, parental psychiatric history, and socioeconomic status. Am. J. Epidemiol. 161, 916-925. discussion: 26-28. doi: 10.1093/aje/kwi123 
Lauritsen, M. B., Pedersen, C. B., and Mortensen, P. B. (2005). Effects of familial risk factors and place of birth on the risk of autism: a nationwide register-based study. J. Child Psychol. Psychiatry 46, 963-971. doi: 10.1111/j.1469-7610.2004.00391.x

Lee, B. K., Gardner, R. M., Dal, H., Svensson, A., Galanti, M. R., Rai, D., et al. (2012). Brief report: maternal smoking during pregnancy and autism spectrum disorders. J. Autism Dev. Disord. 42, 2000-2005. doi: 10.1007/s10803-011-1425-4

Leonard, H., de Klerk, N., Bourke, J., and Bower, C. (2006). Maternal health in pregnancy and intellectual disability in the offspring: a population-based study. Ann. Epidemiol. 16, 448-454. doi: 10.1016/j.annepidem.2005.05.002

Li, D., Liu, L., and Odouli, R. (2009a). Presence of depressive symptoms during early pregnancy and the risk of preterm delivery: a prospective cohort study. Hum. Reprod. 24, 146-153. doi: 10.1093/humrep/den 342

Li, J., Vestergaard, M., Obel, C., Christensen, J., Precht, D. H., Lu, M., et al. (2009b). A Nationwide study on the risk of autism after prenatal stress exposure to maternal bereavement. Pediatrics 123, 1102-1107.

Limperopoulos, C., Bassan, H., Sullivan, N. R., Soul, J. S., Robertson, R. L., Jr., Moore, M., et al. (2008). Positive screening for autism in ex-preterm infants: prevalence and risk factors. Pediatrics 121, 758-765. doi: 10.1542/peds.2007-2158

Lintas, C., Altieri, L., Lombardi, F., Sacco, R., and Persico, A. M. (2010). Association of autism with polyomavirus infection in postmortem brains. J. Neurovirol. 16, 141-149. doi: 10.3109/13550281003685839

Lintas, C., Sacco, R., and Persico, A. M. (2012). Genome-wide expression studies in autism spectrum disorder, Rett syndrome, and Down syndrome. Neurobiol. Dis. 45, 57-68. doi: 10.1016/j.nbd.2010.11.010

Ludewig, B., Krebs, P., Metters, H., Tatzel, J., Türeci, Ö., and Sahin, U. (2004). Molecular characterization of virus-induced autoantibody responses. J. Exp. Med. 200, 637-646.

Malkova, N. (2010). Maternal Immune Activation Causes a Deficit in Social and Communicative Behavior in Male Mouse Offspring. San Diego, CA: Soc Neurosci. [cited 2013 18/02/2013]. Available online at: http://www.sfn.org/ /am2010/pdf/final_program/final_ program_b5.pdf. doi: $10.1146 /$ annurev.ne.18.030195.000533

Malkova, N. V., Yu, C. Z., Hsiao, E. Y., Moore, M. J., and Patterson, P. H. (2012). Maternal immune activation yields offspring displaying mouse versions of the three core symptoms of autism. Brain Behav. Immun. 26, 607-616. doi: 10.1016/j.bbi.2012.01.011

Markowitz, P. I. (1983). Autism in a child with congenital cytomegalovirus infection. J. Autism Dev. Disord. 13, 249-253. doi: 10.1007/BF01531564

Martin, L. A., Ashwood, P., Braunschweig, D., Cabanlit, M., Van de Water, J., and Amaral, D. G. (2008). Stereotypies and hyperactivity in rhesus monkeys exposed to $\operatorname{IgG}$ from mothers of children with autism. Brain Behav. Immun. 22, 806-816. doi: 10.1016/j.bbi.2007.12.007

Matson, J. L., and Kozlowski, A. M. (2011). The increasing prevalence of autism spectrum disorders. Res. Autism Spectr. Disord. 5, 418-425. doi: 10.1016/j.rasd.2010.06.004

McCowan, L. M., Dekker, G. A., Chan, E., Stewart, A., Chappell, L. C., Hunter, M., et al. (2009). Spontaneous preterm birth and small for gestational age infants in women who stop smoking early in pregnancy: prospective cohort study. BMJ 338:b1081. doi: 10.1136/bmj.b1081

Meguid, N. A., Hashish, A. F., Anwar, M., and Sidhom, G. (2010). Reduced serum levels of 25hydroxy and 1, 25-dihydroxy vitamin $D$ in Egyptian children with autism. J. Altern. Complement. Med. 16, 641-645. doi: 10.1089/acm.2009.0349

Meyer, U., and Feldon, J. (2010). Epidemiology-driven neurodevelopmental animal models of schizophrenia. Prog. Neurobiol. 90, 285-326. doi: 10.1016/j.pneurobio. 2009.10.018

Meyer, U., Feldon, J., and Dammann, O. (2011). Schizophrenia and autism: both shared and disorder-specific pathogenesis via perinatal inflammation. Pediatr. Res. 69(5 Pt 2), 26R-33R. doi: 10.1203/PDR.0b013e318212c196

Meyer, U., Yee, B. K., and Feldon, J. (2007). The neurodevelopmental impact of prenatal infections at different times of pregnancy: the earlier the worse. Neuroscientist 13, 241-256. doi: 10.1177/1073858406296401

Moore, T., Johnson, S., Hennessy, E., and Marlow, N. (2012).
Screening for autism in extremely preterm infants: problems in interpretation. Dev. Med. Child Neurol. 54, 514-520. doi: 10.1111/j.1469-8749.2012.04265.x

Morgan, J. T., Chana, G., Pardo, C. A., Achim, C., Semendeferi, K., Buckwalter, J., et al. (2010). Microglial activation and increased microglial density observed in the dorsolateral prefrontal cortex in autism. Biol. Psychiatry 68 368-376. doi: 10.1016/j.biopsych. 2010.05.024

Movsas, T. Z., and Paneth, N. (2012). The effect of gestational age on symptom severity in children with autism spectrum disorder. J. Autism Dev. Disord. 42, 2431-2439. doi: 10.1007/s10803-012-1501-4

Nelson, K. B., Dambrosia, J. M., Iovannisci, D. M., Cheng, S. Grether, J. K., and Lammer, E. (2005). Genetic polymorphisms and cerebral palsy in very preterm infants. Pediatr. Res. 57, 494-499. doi: 10.1203/ 01.PDR.0000156477.00386.E7

Ng, S. P., and Zelikoff, J. T. (2007). Smoking during pregnancy: subsequent effects on offspring immune competence and disease vulnerability in later life. Reprod. Toxicol. 23, 428-437. doi: 10.1016/j.reprotox.2006.11.008

Oakley, A., Rajan, L., and Grant, A. (1990). Social support and pregnancy outcome. Br. J. Obstet. Gynaecol. 97, 155-162. doi: 10.1111/ j.1471-0528.1990.tb01741.x

Pararas, M. V., Skevaki, C. L., and Kafetzis, D. A. (2006). Preterm birth due to maternal infection: causative pathogens and modes of prevention. Eur. J. Clin. Microbiol. Infect. Dis. 25, 562-569.

Parner, E. T., Baron-Cohen, S., Lauritsen, M. B., Jorgensen, M., Schieve, L. A., Yeargin-Allsopp, M., et al. (2012). Parental age and autism spectrum disorders. Ann. Epidemiol. 22, 143-150. doi: 10.1016/j.annepidem.2011.12.006

Patrick, L. A., and Smith, G. N. (2002). Proinflammatory cytokines: a link between chorioamnionitis and fetal brain injury. J. Obstet. Gynaecol. Can. 24, 705-709.

Patterson, P. H. (2002). Maternal infection: window on neuroimmune interactions in fetal brain development and mental illness. Curr. Opin. Neurobiol. 12, 115-118. doi: 10.1016/S0959-438800299-4

Patterson, P. H. (2009). Immune involvement in schizophrenia and autism: etiology, pathology and animal models. Behav.
Brain Res. 204, 313-321. doi: 10.1016/j.bbr.2008.12.016

Pinto-Martin, J. A., Levy, S. E., Feldman, J. F., Lorenz, J. M., Paneth, N., and Whitaker, A. H. (2011). Prevalence of autism spectrum disorder in adolescents born weighing $<2000$ grams. Pediatrics 128, 883-891. doi: 10.1542/peds.2010-2846

Rai, D., Golding, J., Magnusson, C., Steer, C., Lewis, G., and Dalman, C. (2012). Prenatal and early life exposure to stressful life events and risk of autism spectrum disorders: population-based studies in Sweden and England. PLoS ONE 7:e38893. doi: 10.1371/journal.pone.0038893

Redline, R. W., Wilson-Costello, D., Borawski, E., Fanaroff, A. A., and Hack, M. (1998). Placental lesions associated with neurologic impairment and cerebral palsy in very lowbirth-weight infants. Arch. Pathol. Lab. Med. 122, 1091-1098.

Redline, R. W., Wilson-Costello, D., Borawski, E., Fanaroff, A. A., and Hack, M. (2000). The relationship between placental and other perinatal risk factors for neurologic impairment in very low birth weight children. Pediatr. Res. 47, 721-726. doi: 10.1203/00006450-20000600000007

Reichenberg, A., Gross, R., Weiser, M., Bresnahan, M., Silverman, J., Harlap, S., et al. (2006). Advancing paternal age and autism. Arch. Gen. Psychiatry 63, 1026-1032. doi: 10.1001/archpsyc.63.9.1026

Rey, E., and Couturier, A. (1994). The prognosis of pregnancy in women with chronic hypertension. Am. J. Obstet. Gynecol. 171, 410-416. doi: 10.1016/0002-937890276-3

Rizzo, T. A., Metzger, B. E., Dooley, S. L., and Cho, N. H. (1997). Early malnutrition and child neurobehavioral development: insights from the study of children of diabetic mothers. Child Dev. 68, 26-38. doi: 10.2307/1131922

Romero, R., Chaiworapongsa, T., and Espinoza, J. (2003). Micronutrients and intrauterine infection, preterm birth and the fetal inflammatory response syndrome. J. Nutr. 133(5 Suppl. 2), 1668S-1673S.

Romero, R., Espinoza, J., Goncalves, L. F., Kusanovic, J. P., Friel, L. A., and Nien, J. K. (2006). Inflammation in preterm and term labour and delivery. Semin. Fetal Neonatal Med. 11, 317-326. doi: 10.1016/j.siny.2006.05.001

Rostene, W., Kitabgi, P., and Parsadaniantz, S. M. (2007). Chemokines: a new class of 
neuromodulator. Nat. Rev. Neurosci. 8, 895-903. doi: 10.1038/nrn2255

Roza, S. J., van Batenburg-Eddes, T., Steegers, E. A., Jaddoe, V. W., Mackenbach, J. P., Hofman, A., et al. (2010). Maternal folic acid supplement use in early pregnancy and child behavioural problems: the generation $\mathrm{R}$ study. Br. J. Nutr. 103, 445-452. doi: 10.1017/S0007114509991954

Sadeharju, K., Knip, M., Hiltunen, M., Akerblom, H. K., and Hyoty, H. (2003). The HLA-DR phenotype modulates the humoral immune response to enterovirus antigens. Diabetologia 46, 1100-1105. doi: 10.1007/s00125-003-1157-x

Salihu, H. M., Lynch, O., Alio, A. P., and Liu, J. (2008). Obesity subtypes and risk of spontaneous versus medically indicated preterm births in singletons and twins. Am. J. Epidemiol. 168, 13-20. doi: 10.1093/aje/kwn092

Samara, M., Marlow, N., and Wolke, D. (2008). Pervasive behavior problems at 6 years of age in a total-population sample of children born at $</=25$ weeks of gestation. Pediatrics 122, 562-573. doi: 10.1542/peds.2007-3231

Sandin, S., Hultman, C. M., Kolevzon, A., Gross, R., MacCabe, J. H., and Reichenberg, A. (2012). Advancing maternal age is associated with increasing risk for autism: a review and meta-analysis. J. Am. Acad. Child Adolesc. Psychiatry 51, 477-486.e1.

Sargent, I. L. (1993). Maternal and fetal immune responses during pregnancy. Exp. Clin. Immunogenet. 10, 85-102.

Schendel, D. E., Autry, A., Wines, R., and Moore, C. (2009). The cooccurrence of autism and birth defects: prevalence and risk in a population-based cohort. Dev. Med. Child Neurol. 51, 779-786. doi: 10.1111/j.1469-8749.2009.03310.x

Schendel, D., and Bhasin, T. K. (2008). Birth weight and gestational age characteristics of children with autism, including a comparison with other developmental disabilities. Pediatrics 121, 1155-1164. doi: 10.1542/ peds.2007-1049

Schieve, L. A., Rice, C., Devine, O., Maenner, M. J., Lee, L. C., Fitzgerald, R., et al. (2011). Have secular changes in perinatal risk factors contributed to the recent autism prevalence increase. Development and application of a mathematical assessment model. Ann. Epidemiol. 21, 930-945. doi: 10.1016/j.annepidem.2011.08.009
Schmidt, R. J., Tancredi, D. J., Ozonoff, S., Hansen, R. L., Hartiala, J., Allayee, H., et al. (2012). Maternal periconceptional folic acid intake and risk of autism spectrum disorders and developmental delay in the CHARGE (CHildhood Autism Risks from Genetics and Environment) case-control study. Am. J. Clin. Nutr. 96, 80-89.

Schwartz, D., Goujard, J., Kaminski, M., and Rumeau-Rouquette, C. (1972). Smoking and pregnancy. Results of a prospective study of 6, 989 women. Rev. Eur. Etud. Clin. Biol. 17, 867-879.

Shah, N. R., and Bracken, M. B. (2000). A systematic review and meta-analysis of prospective studies on the association between maternal cigarette smoking and preterm delivery. Am. J. Obstet. Gynecol. 182, 465-472. doi: 10.1016/S0002937870240-7

Shatrov, J. G., Birch, S. C., Lam, L. T., Quinlivan, J. A., McIntyre, S., and Mendz, G. L. (2010). Chorioamnionitis and cerebral palsy: a meta-analysis. Obstet. Gynecol. 116(2 Pt 1), 387-392. doi: 10.1097/AOG.0b013e3181e90046

Shelton, J. F., Tancredi, D. J., and HertzPicciotto, I. (2010). Independent and dependent contributions of advanced maternal and paternal ages to autism risk. Autism Res. 3, 30-39.

Shi, L., Fatemi, S. H., Sidwell, R. W., and Patterson, P. H. (2003). Maternal influenza infection causes marked behavioral and pharmacological changes in the offspring. J. Neurosci. 23, 297-302.

Shinohe, A., Hashimoto, K., Nakamura, K., Tsujii, M., Iwata, Y., Tsuchiya, K. J., et al. (2006). Increased serum levels of glutamate in adult patients with autism. Prog. Neuropsychopharmacol. Biol. Psychiatry 30, 1472-1477. doi: 10.1016/j.pnpbp.2006.06.013

Short, S. J., Lubach, G. R., Karasin, A. I., Olsen, C. W., Styner, M., Knickmeyer, R. C., et al. (2010). Maternal influenza infection during pregnancy impacts postnatal brain development in the rhesus monkey. Biol. Psychiatry 67, 965-973. doi: 10.1016/j.biopsych. 2009.11.026

Siega-Riz, A. M., Hartzema, A. G., Turnbull, C., Thorp, J., McDonald, T., and Cogswell, M. E. (2006). The effects of prophylactic iron given in prenatal supplements on iron status and birth outcomes: a randomized controlled trial. Am. J. Obstet. Gynecol. 194, 512-519. doi: 10.1016/j.ajog.2005.08.011
Simpson, W. J. (1957). A preliminary report on cigarette smoking and the incidence of prematurity. Am. J. Obstet. Gynecol. 73, 807-815.

Singer, H. S., Morris, C., Gause, C., Pollard, M., Zimmerman, A. W., and Pletnikov, M. (2009). Prenatal exposure to antibodies from mothers of children with autism produces neurobehavioral alterations: a pregnant dam mouse model. J. Neuroimmunol. 211, 39-48. doi: 10.1016/j.jneuroim.2009.03.011

Smith, S. E., Li, J., Garbett, K., Mirnics, K., and Patterson, P. H. (2007). Maternal immune activation alters fetal brain development through interleukin-6. J. Neurosci. 27, 10695-10702. doi: 10.1523/JNEUROSCI.2178-07.2007

Srinivas, S. K., Ma, Y., Sammel, M. D., Chou, D., McGrath, C., Parry, S., et al. (2006). Placental inflammation and viral infection are implicated in second trimester pregnancy loss. Am. J. Obstet. Gynecol. 195, 797-802. doi: 10.1016/j.ajog.2006.05.049

Stephens, B. E., Bann, C. M., Watson, V. E., Sheinkopf, S. J., Peralta-Carcelen, M., Bodnar, A., et al. (2012). Screening for autism spectrum disorders in extremely preterm infants. J. Dev. Behav. Pediatr. 33, 535-541. doi: 10.1097/DBP.0b013e31825fd0af

Stern, H., and Tucker, S. M. (1973). Prospective study of cytomegalovirus infection in pregnancy. Br. Med. J. 2, 268-270. doi: 10.1136/bmj.2.5861.268

Stubbs, E. G. (1978). Autistic symptoms in a child with congenital cytomegalovirus infection. J. Autism Child Schizophr. 8, 37-43. doi: 10.1007/BF01550276

Stubbs, G. (1995). Interferonemia and autism. J. Autism Dev. Disord. 25, 71-73. doi: 10.1007/BF02178169

Sweeten, T. L., Posey, D. J., and McDougle, C. J. (2004). Brief report: autistic disorder in three children with cytomegalovirus infection. J. Autism Dev. Disord. 34, 583-586. doi: 10.1007/s10803-004-2552-y

Thiriez, G., Bouhaddi, M., Mourot, L., Nobili, F., Fortrat, J. O., Menget, A., et al. (2009). Heart rate variability in preterm infants and maternal smoking during pregnancy. Clin. Auton. Res. 19, 149-156. doi: 10.1007/s10286-009-0003-8

Uchide, N., Ohyama, K., Bessho, T., and Toyoda, H. (2005). Induction of pro-inflammatory cytokine gene expression and apoptosis in human chorion cells of fetal membranes by influenza virus infection: possible implications for maintenance and interruption of pregnancy during infection. Med. Sci. Monit. 11, RA7-RA16.

Voineagu, I., Wang, X., Johnston, P., Lowe, J. K., Tian, Y., Horvath, S., et al. (2011). Transcriptomic analysis of autistic brain reveals convergent molecular pathology. Nature 474, 380-384. doi: $10.1038 /$ nature 10110

Wegiel, J., Kuchna, I., Nowicki, K., Imaki, H., Marchi, E., Ma, S. Y., et al. (2010). The neuropathology of autism: defects of neurogenesis and neuronal migration, and dysplastic changes. Acta Neuropathol. 119, 755-770. doi: 10.1007/s00401010-0655-4

Wharton, K. N., Pinar, H., Stonestreet, B. S., Tucker, R., McLean, K. R., Wallach, M., et al. (2004). Severe umbilical cord inflammation-a predictor of periventricular leukomalacia in very low birth weight infants. Early Hum. Dev. 77, 77-87. doi: 10.1016/j.earlhumdev.2004.02.001

Williams, K., Helmer, M., Duncan, G. W., Peat, J. K., and Mellis, C. M. (2008a). Perinatal and maternal risk factors for autism spectrum disorders in New South Wales, Australia. Child Care Health Dev. 34, 249-256. doi: 10.1111/j.13652214.2007.00796.x

Williams, K., MacDermott, S., Ridley, G., Glasson, E., Wray, J. A. (2008b) The prevalence of autism in Australia. Can it be established from existing data? J. Paediatr. Child Health. 44, 504-510. doi: 10.1111/j.1440-1754.2008.01331.x

Wills, S., Cabanlit, M., Bennett, J., Ashwood, P., Amaral, D., and Van de Water, J. (2007). Autoantibodies in autism spectrum disorders (ASD). Ann. N.Y. Acad. Sci. 1107, 79-91. doi: 10.1196/annals.1381.009

Wing, L., and Potter, D. (2002). The epidemiology of autistic spectrum disorders: is the prevalence rising. Ment. Retard. Dev. Disabil. Res. Rev. 8, 151-161. doi: 10.1002/mrdd.10029

Wu, Y. W. (2002). Systematic review of chorioamnionitis and cerebral palsy. Ment. Retard. Dev. Disabil. Res. Rev. 8, 25-29. doi: 10.1002/mrdd. 10003

Wu, Y. W., Croen, L. A., Torres, A. R., Van De Water, J., Grether, J. K., and Hsu, N. N. (2009). Interleukin6 genotype and risk for cerebral palsy in term and near-term infants. Ann. Neurol. 66, 663-670. doi: 10.1002/ana.21766

Yamashita, Y., Fujimoto, C., Nakajima, E., Isagai, T., and Matsuishi, T. (2003). Possible association between congenital cytomegalovirus 
infection and autistic disorder. J. Autism Dev. Disord. 33, 455-459. doi: 10.1023/A:1025023131029

Yoon, B. H., Jun, J. K., Romero, R., Park, K. H., Gomez, R., Choi, J. H., et al. (1997a). Amniotic fluid inflammatory cytokines (interleukin-6, interleukin-1beta, and tumor necrosis factor-alpha), neonatal brain white matter lesions, and cerebral palsy. Am. J. Obstet. Gynecol. 177, 19-26. doi: 10.1016/S0002-937870432-0

Yoon, B. H., Kim, C. J., Romero, R., Jun, J. K., Park, K. H., Choi, S. T., et al. (1997b). Experimentally induced intrauterine infection causes fetal brain white matter lesions in rabbits. Am. J. Obstet. Gynecol. 177, 797-802. doi: 10.1016/S0002-937870271-0
Yoon, B. H., Romero, R., Moon, J. B., Shim, S. S., Kim, M., Kim, G., et al. (2001). Clinical significance of intra-amniotic inflammation in patients with preterm labor and intact membranes. Am. J. Obstet. Gynecol. 185, 1130-1136. doi: 10.1067/mob.2001.117680

Yoon, B. H., Romero, R., Park, J. S., Kim, C. J., Kim, S. H., Choi, J. H., et al. (2000). Fetal exposure to an intra-amniotic inflammation and the development of cerebral palsy at the age of three years. Am. J. Obstet. Gynecol. 182, 675-681. doi: 10.1067/mob.2000.104207

Zenclussen, A. C., Schumacher, A., Zenclussen, M. L., Wafula, P., and Volk, H. D. (2007). Immunology of pregnancy: cellular mechanisms allowing fetal survival within the maternal uterus. Expert Rev. Mol. Med. 9, 1-14. doi: 10.1017/S1462399407000294

Zhu, Y., Yu, T., Zhang, X. C., Nagasawa, T., Wu, J. Y., and Rao, Y. (2002). Role of the chemokine SDF-1 as the meningeal attractant for embryonic cerebellar neurons. Nat. Neurosci. 5, 719-720.

Conflict of Interest Statement: The authors declare that the research was conducted in the absence of any commercial or financial relationships that could be construed as a potential conflict of interest.

Received: 01 April 2013; accepted: 26 June 2013; published online: 22 July 2013.
Citation: Meldrum SJ, Strunk T, Currie A, Prescott SL, Simmer $K$ and Whitehouse AJO (2013) Autism spectrum disorder in children born preterm-role of exposure to perinatal inflammation. Front. Neurosci. 7:123. doi: 10.3389/fnins.2013.00123

This article was submitted to Frontiers in Neuroendocrine Science, a specialty of Frontiers in Neuroscience.

Copyright (C) 2013 Meldrum, Strunk, Currie, Prescott, Simmer and Whitehouse. This is an open-access article distributed under the terms of the Creative Commons Attribution License, which permits use, distribution and reproduction in other forums, provided the original authors and source are credited and subject to any copyright notices concerning any third-party graphics etc. 